\title{
Onion (Allium cepa L.) plant growth response to varying levels of leaf and root damages $-\mathrm{a}$ preliminary study
}

\begin{abstract}
A biotic and biotic stresses can cause severe damages to leaves and/or roots of plants leading to reduction in productivity and plant death. A greenhouse pot-experiment was performed to determine the interactive effects of leaf and root damages on onion (Allium сера L. 'Braddock') plant growth and productivity. The treatments were: 1) leaf damage (LD: 0, 25, 50, 75 and 100\%); and 2) root damage (RD: 0, 50 and 100\%) at transplanting. Onion plants with LD $75 \%$ or $100 \%$ under severeRD $100 \%$ exhibited the least plant growth rate, and reduced bulbing ratio and bulb fresh weight compared to control intact plants. Moderate leaf damage i.e., LD 25\% combined with severe root damage RD 100\% had the highest plant growth rate and bulbing ratio compared to the other treatments suggesting that plants with severe root damage, but moderate leaf damage promoted onion plant growth. In conclusion, this preliminary study showed that combined leaf and root damage or root damage alone significantly $(\mathrm{P}<0.05)$ reduced onion plant growth and productivity. However, leaf damage alone did not significantly $(\mathrm{P}>0.05)$ reduce onion plant growth and productivity. Future work will investigate plant morpho-physiological response.
\end{abstract}

Volume 5 Issue 3 - 202I

\section{LiWen, Mercy ljenyo, Lord Abbey}

Department of Plant, Food, and Environmental Sciences, Faculty of Agriculture, Dalhousie University, Canada

\begin{abstract}
Correspondence: Lord Abbey, Department of Plant, Food, and Environmental Sciences, Faculty of Agriculture, Dalhousie University, 50 Pictou Road, Truro B2N 5E3, Nova Scotia, Canada, Emailloab07@gmail.com
\end{abstract}

Received: May 03, 202I | Published: May 17, 2021

Keywords: leaf damage, root damage, abiotic stress, bulbing ratio, plant growth rate

\section{Introduction}

Onion (Allium cepa L.) is a biennial, horticultural plant which belongs to the genus Allium and family Amaryllidaceae (formerly Alliaceae). Alliums have more than 900 species. ${ }^{1}$ Onion bulbis valued for its culinary and medicinal properties. It is used for cooking due to its strong flavor from high sulfur compounds derived from four non-protein sulfur amino acid collectively termed S-alk(en)ylcysteine sulfoxides (CSO). ${ }^{2}$ CSO compounds are known to have medicinal health benefits and antimicrobial properties due to the concentration of flavonoid antioxidant (i.e., quercetin 3-glucoside), which is higher (43.85 mg/g DW) than quercetin $(30.08 \mathrm{mg} / \mathrm{g} \mathrm{DW}) .{ }^{2}$ Agronomically, onion is recognized as the most widely adapted vegetable crop that can be grown under wide range of climatic conditions (i.e. tropics to subarctic regions). ${ }^{3}$

Plant growth, yield and quality of onions are affected by genotypic, biotic and abiotic factors. ${ }^{4,5}$ Abbey et al. ${ }^{6}$ found that leaf damage of shallots at bulb initiation stage reduced shallot (Allium ascalonicum L.) bulb yield. The natural growth architecture of onion makes it susceptible to foliage damage by pests and diseases, strong winds and farm equipment, human and animal movements, which can impose stress on the plants. Additionally, onion plant has fibrous root system and is prone to root damages during transplanting. Although leaf and root damages can have severe effect on plant growth and yield, it is most likely that their combined effects can have implications for plant survival under stressful conditions.

According to Welbaum, ${ }^{7}$ onion transplants produce high yield under unfavorable conditions. Other research reported higher growth and bulb yield of bare-root transplants of onion seedlings. ${ }^{8}$ However, the critical stage at which the interaction of leaf and root damages will negatively impact plant growth and onion bulb is unknown. Therefore, this preliminary study investigated the combined effect of leaf and root damages on onion 'Braddock' plant growth and bulb yield in a greenhouse pot-experiment.

\section{Materials and methods}

The greenhouse pot-experiment was performed at the Department of Plant, Food, and Environmental Sciences. Seeds of yellow onion 'Braddock' were obtained from Bejo Zadenb.v., Netherlands. The Promix BX (Premier Horticulture Inc., Quaketown, PA) was purchased from Co-operative Store, Truro, NS. Promix BX is a general purpose growing medium potting mix made from $75 \%-85 \%$ sphagnum peat moss, horticultural-grade perlite, vermiculite, limestone, and wetting agent.

Four-week-old onion seedlings were transplanted in to $3.84-\mathrm{L}$ pots filled with $400 \mathrm{~g}$ of Promix BX. Prior to transplanting, the leaves and roots of onion seedlings were cut with a sharp pair of scissors at varying lengths from the tip to the base to simulate different severity of leaf (LD) and root (RD) damages. The tissue damage treatments were: (1) LD at $0,25,50,75$ and $100 \%$ ); and (2) RD at 0,50 and $100 \%$ arranged in a 2 -factor randomized complete block design with four replications. Each pot contained four plants per treatment $(n=16)$. Vermicompost i.e., $20 \mathrm{~g} /$ pot at planting, and compound fertilizer i.e., nitrogen-phosphorus-potassium (NPK) 20-20-20 fertilizer at $4 \mathrm{~g} / \mathrm{pot}$ were applied to all plants at 3, 6 and 8 weeks after transplanting. The pots were placed on benches in the greenhouse, and they were rearranged periodically (every 2-3 weeks) on the benches to minimize any unforeseen environmental variations in the greenhouse. Watering was done every other day until harvest.

\section{Data collection and statistical analysis}

Data on plant growth rate, leaf length, plant height, pseudostem diameter, bulb diameter, plant fresh weight, leaf fresh weight, leaf dry weight, and leaf area were collected at 10 weeks after transplanting.

The calculations were:

Leaf growth rate $=[$ current leaf length - Initial leaf length $/$ Initial leaf length] x 100 
The bulb ratio $=$ Bulb diameter/ Pseudo stem diameter.

The leaf mass density= Leaf dry weight $/$ Leaf fresh weight

Analysis of variance (ANOVA) was carried out using PROC MIXED of SAS (ver. 9.4, SAS institute Inc., Cary, NC). The treatment mean effect were compared by LSD method $(\alpha<0.05)$ when the ANOVA indicated statistical difference between treatment means at $\mathrm{P} \leq 0.05$.

\section{Results and discussion}

From Figure 1, all seedlings with damaged roots were actively forming new roots, which was demonstrated by the white adventitious roots. It seemed bulbing was delayed by severe damage of leaves as shown in Figure 1.
The growth rates of plants with intact roots were similar irrespective of leaf damage but was increased slightly for plants whose leaves were severely damaged e.g., LD75\% RD0\% and LD $100 \%$ R0\% from the 9th day after transplanting compared to the other treatments (Figure 2).

For RD50\%, plant growth rate was not significantly $(\mathrm{P}<0.05)$ different until three days after transplanting when LD25\% RD50\% increased slightly as compared to the other treatments (Figure 2). LD0\% RD100\%, LD25\% RD100\% and LD50\% RD100\% showed similar growth trend. On the other hand, onion plant growth rate for treatments $\mathrm{LD} 75 \% \mathrm{RD} 100 \%$ and $\mathrm{LD} 100 \% \mathrm{RD} 100 \%$ were the least until after 21 days of transplanting when the latter grew rapidly and exceeded the former due to new growth after recovery from stress (Figure 2).
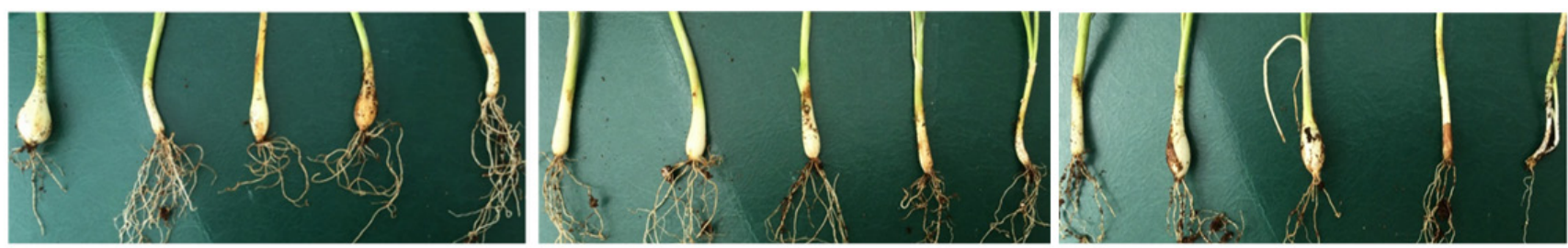

LD0\% $\quad$ LD25\% $\quad$ LD50\% $\quad$ LD75\% $\quad$ LD100\% $\quad$ LD0\% $\quad$ LD25\% $\quad$ LD50\% $\quad$ LD75\% $\quad$ LD100\% $\quad$ LD0\% $\quad$ LD25\% $\quad$ LD50\% $\quad$ LD75\% $\quad$ LD100\%

Figure I Onion 'Braddock' plant root growth and bulbingas affected by leaf and root damages. LD, leaf damage and RD, root damage.
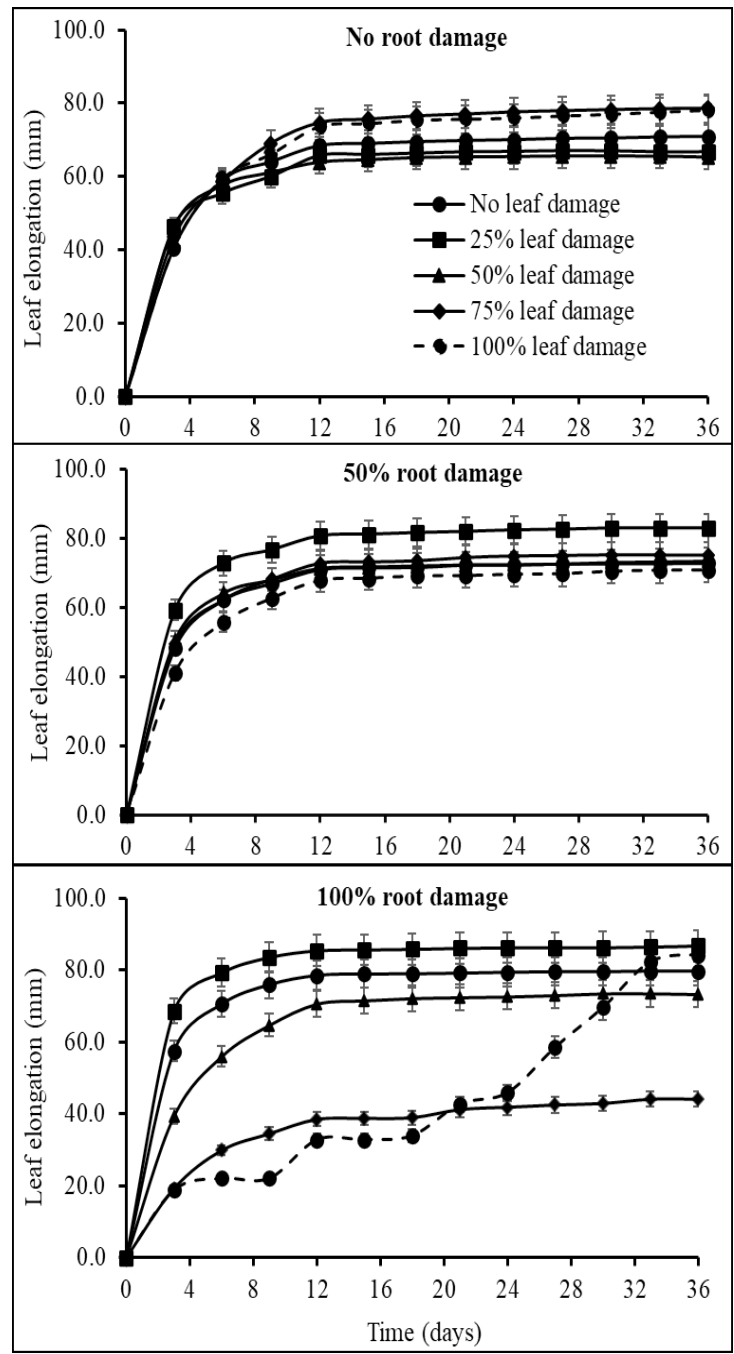

Figure 2 Onion 'Braddock' leaf growth rate as affected by leaf and root damages.

Citation: Wen L, ljenyo M,Abbey L. Onion (Allium cepa L.) plant growth response to varying levels of leaf and root damages - a preliminary study. Horticult Int J. 202I;5(3):107-IIO. DOI: I0.15406/hii.202I.05.00213 
The interaction of $\mathrm{LD}$ and $\mathrm{RD}$ on plant height was significant $(\mathrm{P}<0.05)$ (Table 1). The average plant height of all RD0\% treatments was $45.6 \mathrm{~cm}$, which was greater than those of RD $50 \%$ and RD $100 \%$ by approximately, $36.0 \mathrm{~cm}$ and $35.9 \mathrm{~cm}$, respectively. LD25\% RD100\%, LD75\% RD50\%, LD50\% RD100\% and LD100\% RD50\% had the least plant height compared to LD100\% RD0\% by $57.9 \mathrm{~cm}$ (Table 1). It can be suggested that RD $\%$ treatments with severe LD tended to take more time to recover and get to the re-growth phase. Leaf mass density of RD0\% was $0.06847 \mathrm{mg} / \mathrm{g}$, which was significantly $(\mathrm{P}<0.05)$ different from RD50\% and RD100\% (Table 1). Also, RD0\% treatment had the largest leaf area, especially when compared to RD100\%. The results indicated that onion plants with intact roots can absorb and transport the required materials from the growing medium for plant use. These can explain the present findings i.e., the resultant production of large leaf sizes and increased number of leaves for improved assimilate production and storage in swollen onion bulbs.

Table I Onion 'Braddock' plant growth and yield components as affected by leaf and root damages

\begin{tabular}{|c|c|c|c|c|c|c|c|c|c|c|c|c|c|c|c|}
\hline \multirow[t]{2}{*}{ Treatment } & \multicolumn{3}{|c|}{$\begin{array}{l}\text { Plant height } \\
\text { (cm) }\end{array}$} & \multicolumn{3}{|c|}{ Leaf area $\left(\mathrm{m}^{2}\right)$} & \multicolumn{3}{|c|}{$\begin{array}{l}\text { Leaf mass density } \\
(\mathrm{mg} / \mathrm{g})\end{array}$} & \multicolumn{3}{|c|}{ Bulbing ratio } & \multicolumn{3}{|c|}{$\begin{array}{l}\text { Bulb fresh } \\
\text { weight }(\mathrm{g})\end{array}$} \\
\hline & RD 0\% & $\begin{array}{l}\text { RD } \\
\mathbf{5 0 \%}\end{array}$ & $\begin{array}{l}\text { RD } \\
100 \%\end{array}$ & RD 0\% & $\begin{array}{l}\text { RD } \\
\mathbf{5 0} \%\end{array}$ & $\begin{array}{l}\text { RD } \\
100 \%\end{array}$ & RD 0\% & $\begin{array}{l}\text { RD } \\
\mathbf{5 0} \%\end{array}$ & $\begin{array}{l}\text { RD } \\
100 \%\end{array}$ & RD 0\% & $\begin{array}{l}\text { RD } \\
\mathbf{5 0 \%}\end{array}$ & $\begin{array}{l}\text { RD } \\
100 \%\end{array}$ & RD 0\% & $\begin{array}{l}\text { RD } \\
\mathbf{5 0 \%}\end{array}$ & $\begin{array}{l}\text { RD } \\
100 \%\end{array}$ \\
\hline LD 0\% & 41.9 & 49.5 & 48.3 & 177.38 & $165.8 \mid$ & 152.65 & 0.071 & 0.068 & 0.063 & 3.5 & 2.8 & 2.6 & 6.22 & 8.55 & 5.64 \\
\hline LD $25 \%$ & 43.1 & 42.3 & 30.4 & 140.26 & 138.49 & 41.21 & 0.061 & 0.063 & 0.068 & 2.9 & 2.9 & 4.6 & 4.26 & 4.41 & 5.12 \\
\hline LD $50 \%$ & 41.7 & 42.7 & 21.3 & 96.16 & 147.08 & 16.86 & 0.068 & 0.063 & 0.053 & 3.2 & 2.6 & 4.4 & 5.72 & 4.82 & 2.75 \\
\hline LD $75 \%$ & 43.3 & 27.9 & 39.5 & 165.67 & 29.92 & 84.5 & 0.075 & 0.062 & 0.063 & 3 & 3.7 & 1.7 & 4.27 & 2.26 & 1.74 \\
\hline LD $100 \%$ & 57.9 & 27.9 & 40.2 & 264.14 & 15.11 & 102.68 & 0.067 & 0.059 & 0.063 & 1.9 & 4.2 & 1.3 & 5.45 & 1.88 & 0.57 \\
\hline Mean & 45.6 & 36 & 35.9 & 168.72 & 99.28 & 79.58 & 0.068 & 0.063 & 0.062 & 2.9 & 3.3 & 2.9 & 5.18 & 4.38 & 3.16 \\
\hline \multicolumn{16}{|c|}{ Significance level $(\alpha=0.05)$} \\
\hline LD & ns & & & ns & & & ns & & & ns & & & $0.0092^{\text {** }}$ & & \\
\hline RD & ns & & & $0.0442 *$ & & & $0.0209 *$ & & & ns & & & ns & & \\
\hline$L D \times R D$ & $0.0416^{*}$ & & & ns & & & ns & & & $0.0240 *$ & & & ns & & \\
\hline
\end{tabular}

LD, leaf damage; RD, root damage; **significant at I\% level; *significant at 5\% level; ns, no significant difference

The interactive effect of LD and RD had significant $(\mathrm{P}<0.05)$ effect on bulbing ratio. Bulbing ratio of LD75\% RD100\%, LD 100\% RD0\% and $\mathrm{LD} 100 \% \mathrm{RD} 100 \%$ were less than 2, which suggested a delayed bulb formation as compared to other treatments. The bulbing ratio of these three treatments were significantly $(\mathrm{P}<0.05)$ different from those of treatments LD25\% RD100\%, LD50\% RD100\% and L100\% RD50\%, which had high bulbing ratios than the control no damage plants (LD0\% RD0\%) (Table 1). As recorded in Table 1, severe leaf damage resulted in smaller bulb fresh weight. LD0\% treatment was greater and significantly $(\mathrm{P}<0.001)$ different from LD75\% and LD $100 \%$ treatments, but not significantly $(\mathrm{P}>0.05)$ different $\mathrm{LD} 25 \%$ and $\mathrm{LD} 50 \%$ treatments. It was obvious that bulb quality can be negatively affected by single effect of severe leaf damage, which may lead to reduced nutrients accumulation in bulb since photosynthesis can be negatively affected. According to Figure 3, the survival rate of $\mathrm{LD} 25 \% \mathrm{RD} 100 \%$, LD $100 \% \mathrm{RD} 50 \%$ and $\mathrm{LD} 100 \% \mathrm{RD} 100 \%$ was $62.5 \%$, which was lower than those of the other treatments (Figure 3).

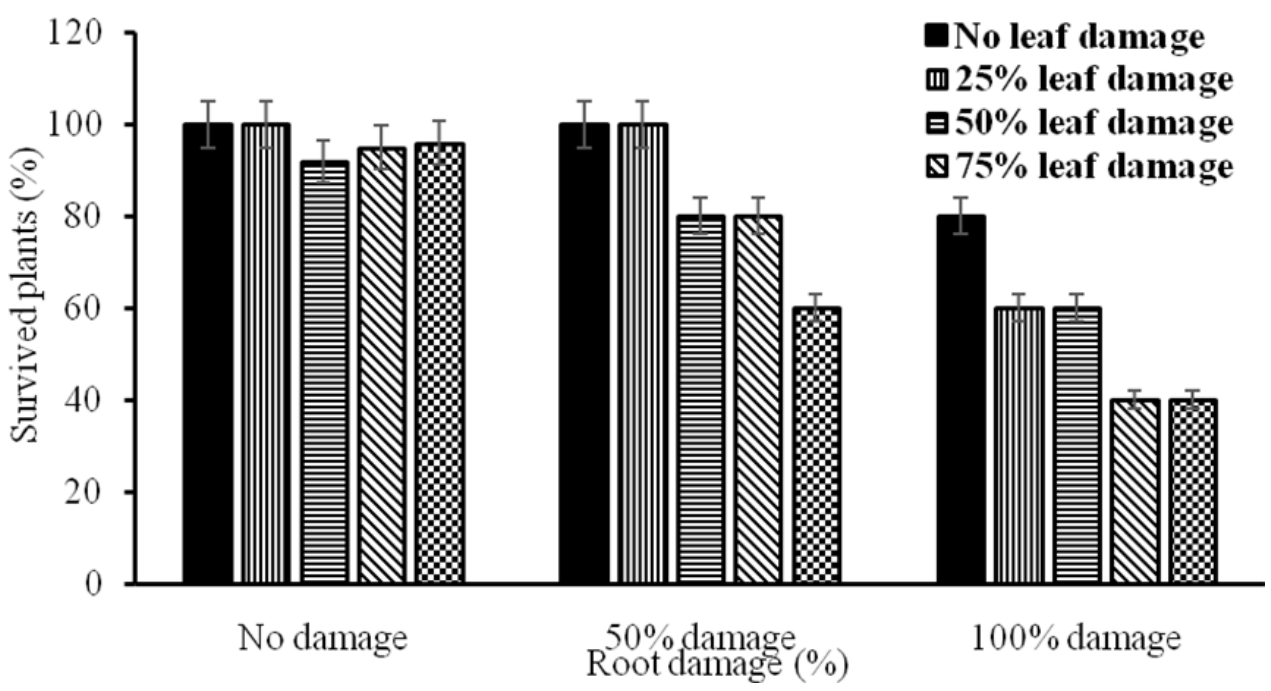

Figure 3 Onion 'Braddock' plant survival level as affected by leaf and root damages. 
Overall, RD100\% and L100\% treatments, irrespective of severity of root damage, had relatively lower survival rate due to physical stress. However, LD25\% RD100\% unexpectedly had less plants that survived.

Based on the results, onion plant with severe leaf and/or root damage had lower growth rate at early stage of seedlings transplant. Also, such damage reduced leaf area, plant height, and leaf mass density. However, re-growth ability was strong, and this accelerated leaf growth once recovered from stress. The recovery process needed time to proceed, which stimulated plants to undergo vegetative growth but delayed bulb formation. LD25\% RD100\%, LD50\% RD100\% and LD100\% RD50\% promoted bulb formation. Thus, phytohormones played a key role in the recovery of damaged tissues of the onion seedlings as previously reported. ${ }^{7,9}$ Generally, severe leaf damage reduced bulb fresh weight as previously reported by Abbey et al (1998). They found that leaf damage at a stage when bulbing has begun would significantly reduce Allium bulb yield.

In conclusion, this preliminary study revealed that severe leaf and root damage scan stress onion plants which as a result, stimulate the plant to recover through various physiological pathways and hormonal stimulations. However, the recovery process can reduce resource allocation for bulb formation. Leaf growth rate, re-growth rate and bulbing ratio are vegetative response parameters controlled by phytohormones, which control plant development. Future work will investigate onion plant morpho-physiological response to tissue damage.

\section{Funding}

None.

\section{Acknowledgments}

None.

\section{Conflicts of interest}

The authors have no conflict of interest for this research.

\section{References}

1. Ekşi G, Gençler Mine A, Özkana G, et al. Review. Garlic and onions: An eastern tale. J Ethnopharmacol. 2020;253:112675.

2. Kwak J-H, Seo JM, Kim N-K, et al. Variation of quercetin glycoside derivatives in three onion (Allium cepa L.) varieties Saudi. J Biol Sci. 2017;24(6):1387-1391.

3. Brewster JL. The structure of edible Allium. In:Onions and other Vegetable Alliums. Second edition. CAB International, Chapter 1:27-47. Wallingford, UK. 2008.

4. Abbey L, Joyce DC, Aked J, et al. Electronic nose evaluation of onion headspace volatiles and bulb quality as affected by nitrogen, sulphur and soil type. Annals of Applied Biology. 2004;145:41-50.

5. Khokhar KM. Environmental and genotypic effects on bulb development in onion - a review. J Hortic Sci and Biotechno L. 2017;92(5):448-454.

6. Abbey L, Kanton R, Braimah H. Susceptibility of shallots to the timing and severity of leaf damage. J Hort Sci. Biotechnol. 1998;73(6):803-805.

7. Welbaum GE. Family Amaryllidaceae, subfamily Allioideace, Onion and garlic. Leeks, shallots and chives. Chapter 14:267-286. InVegetable Production and Practices. CAB International Wallingford, UK. 2015.

8. Prasad B, Maji S, Meena KR. Effect of date of transplanting and mulching on growth, yield and quality of onion (Allium cepa L.) cv. Nasik Red. $J$ Applied Nat Sci. 2017;9(1):94-101.

9. Atif, MJ, Ahanger MA, Amin B, et al. Mechanism of allium crops bulb enlargement in response to photoperiod: a review. Int $J \mathrm{Mol} \mathrm{Sci}$. 2020;21:1325. 